\title{
Preparation of right-side-out plasma membrane vesicles from Penicillium cyclopium: a critical assessment of markers
}

\author{
U. O. Ugalde, ${ }^{1 *}$ A. Hernandez,${ }^{1}$ I. Galindo, ${ }^{1}$ D. Pitt,${ }^{2}$ J. C. Barnes ${ }^{2}$ and G. Wakley ${ }^{2}$ \\ ${ }^{1}$ Unit of Biochemistry, Dept. of Applied Chemistry, University of the Basque Country, Aptdo. 1.072, 20080 \\ San Sebastian, Spain \\ ${ }^{2}$ Dept. of Biological Sciencies, Washington Singer Laboratories, University of Exeter, Exeter EX4 $4 Q G, U K$
}

(Received 17 March 1992; revised 10 June 1992; accepted 23 June 1992)

\begin{abstract}
A plasma membrane fraction was obtained by the combined use of differential centrifugation and aqueous polymer two-phase partitioning techniques. Vanadate-inhibited ATPase and glucan synthase activities were highly enriched in this fraction, although the presence of ATPase activity which was not inhibited by vanadate, nitrate, molybdate, anyimycin A or azide was also detected. Other intracellular membrane marker activities were present at very low or undetectable levels. A further separation step using Percoll density gradient centrifugation resulted in the separation of a fraction which exclusively contained vanadate-inhibited ATPase activity, and was enriched with silicotungstic-acid-staining membrane material. Latency tests performed on the plasma membrane markers showed that the membrane vesicles were in the right-side-out orientation.
\end{abstract}

\section{Introduction}

Isolated plasma membrane vesicles are an important tool for studies of biochemical phenomena associated with this membrane. However, a good understanding of physiological processes, such as transport, ligand binding or changes in membrane potential, requires the use of preparations of unequivocally controlled purity and orientation.

Conventional centrifugation techniques present difficulties when used as the sole means of plasma membrane isolation (Scarborough, 1975), since the inherent small differences between membrane populations, result in partly enriched rather than highly purified plasma membrane preparations (Bowman et al., 1981: Nagahashi et al., 1978).

Selective precipitation methods using concanavalin A binding techniques (Scarborough, 1975; Stroobant \& Scarborough, 1979) or a combination of $\mathrm{pH}$ changes, sonication and centrifugation (Fuhrmann et al., 1976; Franzusoff \& Cirillo, 1983) have elegantly circumvented some of the above problems, but low yields, leaky membrane vesicles and inapplicability in other fungal systems have arisen as respective drawbacks (Bowman $\boldsymbol{e t}$ al., 1981).

Novel techniques combining the use of differential

* Author for correspondence. Tel. 943216600 ; fax 943212236. centrifugation and separation according to surface charge properties have been successfully applied to the isolation of plasma membranes from plant and animal tissues. Aqueous polymer two-phase partition and freeflow electrophoresis not only result in highly purified preparations but also discriminate between membrane vesicles of opposite orientation (Larsson et al., 1984, 1988; Sandelius et al., 1986; Canut et al., 1987).

The uncritical use of single biochemical markers for assessing the purity of plasma membrane fractions has often been questioned and additional methods, such as surface labelling and EM observation, have been used in order to provide confirmatory evidence of plasma membrane purification (Boss \& Ruesink, 1979; Bowman et al., 1981; Scarborough, 1975; Sandelius et al., 1986). Additionally, limited attention to markers of other intracellular organelles which may contaminate plasma membrane fractions has compromised the degree of purity of many preparations. Finally, reports referring to the orientation of plasma membrane vesicle preparations obtained by centrifugation methods only describe the presence of mixed populations of right-side-out and inside-out vesicles (Monk et al., 1989; Randall \& Ruesink, 1983).

Penicillium cyclopium is a filamentous fungus which can switch from vegetative growth to conidiation in liquid culture when $\mathrm{Ca}^{2+}(1-10 \mathrm{mM})$ is present (Ugalde \& Pitt, 1983). $\mathrm{Ca}^{2+}$ uptake by the fungus is biphasic, with 
an initial binding phase followed by uptake. The binding of $\mathrm{Ca}^{2+}$ to the apoplastic surface of the plasma membrane appears to be involved in the induction of conidiation (Ugalde et al., 1990). Thus production of membrane vesicles of controlled orientation is necessary to investigate the molecular nature of this interaction.

Here a procedure is described for the isolation of highly purified right-side-out plasma membrane vesicles using aqueous polymer two-phase partitioning. Purity and orientation criteria involving enzymic and morphological markers are also critically examined.

\section{Methods}

Culture conditions. Penicillium cyclopium (IMI 229034) was cultured in a fermenter (101) with a defined medium at $25^{\circ} \mathrm{C}$ for $24 \mathrm{~h}$ and harvested as described by Ugalde \& Pitt (1983), to obtain $50-60 \mathrm{~g}$ biomass.

Preparation of a microsomal fraction. The biomass was mixed with 50$60 \mathrm{ml}$ homogenizing medium consisting of $5 \mathrm{~mm}$-EDTA, $0.2 \%$ BSA, $0.2 \%$ casein hydrolysate (previously boiled to inactivate proteases), $0.33 \mathrm{M}$-sucrose, $1 \mathrm{~mm}$-dithioerythritol (DTE) and $1 \mathrm{mM}$-PMSF in $50 \mathrm{mM}$-3-[ $N$-morpholino]-2-hydroxypropanesulphonic acid-1,3-bis[Tris-(hydroxymethyl)methylamino]propane (MOPS-BTP), pH 7.5. Cell disruption was achieved in a Potter type homogenizer ( $5 \mathrm{~g}$ batches) with a scintered glass shaft, combining the gradual addition of $15 \mathrm{ml}$ ice-cold homogenizing medium with 20 homogenization thrusts. The resulting crude homogenate $(\mathrm{CH})$ was centrifuged at $5000 \mathrm{~g}$ for $5 \mathrm{~min}$ at $0{ }^{\circ} \mathrm{C}$ to remove cell wall debris and unbroken cells. The supernatant was centrifuged at $10000 \mathrm{~g}$ for $10 \mathrm{~min}$ at $4{ }^{\circ} \mathrm{C}$ to yield a brown and white pellet $(10 \mathrm{Kp})$. The supernatant $(10 \mathrm{Ks})$ was in turn subjected to a $35000 \mathrm{~g}$ centrifugation for $40 \mathrm{~min}$ at the same temperature. The pellet $(35 \mathrm{Kp})$ was resuspended to a final volume of $10 \mathrm{ml}$ in a resuspension medium (RM) consisting of $0.33 \mathrm{M}$-sucrose, $1 \mathrm{mM}$-DTE and $0.1 \mathrm{~mm}$ EDTA in $5 \mathrm{mM}$-potassium phosphate, $\mathrm{pH} 7 \cdot 5$.

Purfication of plasma membranes. The method of Larsson et al., (1987) was essentially followed: $9 \mathrm{~g}$ of the $35 \mathrm{Kp}$ suspension were loaded on to a precooled $\left(0-4{ }^{\circ} \mathrm{C}\right)$ polyethylene glycol $3350 /$ Dextran $\mathrm{T} 500$ two-phase system of $27 \mathrm{~g}$. The resulting $(36 \mathrm{~g})$ system contained $3 \mathrm{~mm}-\mathrm{KCl}$, 0.33 M-sucrose, 0.1 mM-EDTA, 1 mM-DTE, 5 mm-potassium phosphate, $\mathrm{pH} 7 \cdot 8$, and variable polymer concentrations as appropriate.

The phase system was subjected to 20 successive inversions followed by vigorous shaking by hand to ensure thorough mixing of the phases, and allowed to settle for $\mathbf{3 0} \mathrm{min}$ in ice. Distinct phase separation was achieved by centrifugation at $2000 \mathrm{~g}$ for $5 \mathrm{~min}$ in a refrigerated centrifuge with a swing-out rotor.

The resulting upper phase (U1) was withdrawn by aspiration and consecutively separated against two freshly prepared lower phases (L2 \& L3), giving upper phase U3. In a second stage, two freshly made upper phases ( $U^{\prime}$ and $U^{\prime \prime}$ ) were mixed and separated following the same steps, with the lower phases (L1, L2 and L3). The resulting upper phases (U3, U3' and U3") and lower phases (L1, L2 and L3) were pooled into an upper phase fraction and a lower phase fraction, respectively.

Phases were diluted with three volumes of $\mathrm{RM}$ and centrifuged at $100000 \mathrm{~g}$ for $60 \mathrm{~min}$ at $4{ }^{\circ} \mathrm{C}$. The pellets obtained were resuspended in the same medium and assayed immediately for membrane markers.

In some cases, the suspension was layered onto the top of a $27 \%(\mathrm{v} / \mathrm{v})$ Percoll (Pharmacia) solution in the above medium, and centrifuged at $35000 \mathrm{~g}$ for $15 \mathrm{~min}$ in a Kontron TFT 65-13 fixed angle rotor resulting in the simultaneous formation of a density gradient and membrane separation

Marker activities. Plasma membrane ATPase was measured as the disappearance of NADH, enzymically coupled to ATP hydrolysis (Nørby, 1988) as adapted by Palmgren \& Sommarin (1989). An ATP regeneration system was also included and the assay mixture contained $1 \mathrm{~mm}$-DTE, $0.33 \mathrm{M}$-sucrose, $4 \mathrm{~mm}-\mathrm{MgCl}_{2}, 2 \mathrm{~mm}$-ATP, $50 \mu \mathrm{g}$ pyruvate kinase $\mathrm{ml}^{-1}, 25 \mu \mathrm{g}$ lactate dehydrogenase $\mathrm{ml}^{-1}, 10 \mathrm{~mm}$-MOPS-BTP, pH 6.7, and $40-50 \mu \mathrm{g}$ protein. In order to inhibit non-specific phosphatases and mitochondrial and tonoplast ATPases, $0.1 \mathrm{~mm}$ sodium molybdate, $1 \mathrm{mM}$-sodium azide with $0.4 \mu \mathrm{M}$-antimycin $\mathrm{A}$, and $50 \mathrm{~mm}$-sodium nitrate were included, respectively. The difference between activities in the presence and absence of $100 \mu \mathrm{M}$-orthovanadate, an inhibitor of the plasma membrane ATPase (Bowman \& Slayman, 1979), was considered the true value for the activity of this marker.

Tonoplast ATPase activity was measured using the same reaction mixture as described above, except that $\mathrm{pH}$ was adjusted to 7.5 and nitrate was replaced by vanadate. The difference between activities in the presence and absence of $50 \mathrm{~mm}$-sodium nitrate was considered the true value for tonoplast ATPase activity (Sze, 1985).

Cytochrome oxidase activity (marker for the inner mitochondrial membrane) was assayed as described by Cooperstein \& Lazarow (1951). The reduction in $A_{550}$ associated with the oxidation of $0.1 \mathrm{~mm}$

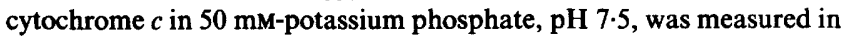
a volume of $0.6 \mathrm{ml}$ after the addition of 5-25 $\mu \mathrm{g}$ protein.

NADPH-cytochrome $c$ oxido-reductase was used as an endoplasmic reticulum marker (Schekman, 1982). The reduction of cytochrome $c$ was measured at $550 \mathrm{~nm}$ (Hodges \& Leonard, 1974). The $0.6 \mathrm{ml}$ reaction mixture contained $0.45 \mathrm{mM}$-cytochrome $c, 50 \mathrm{mM}$-potassium phosphate, pH 7.2, $3 \mathrm{~mm}-\mathrm{NADPH}$, plus $50 \mathrm{~mm}-\mathrm{NaCN}$ and $0.4 \mu \mathrm{M}-$ antimycin $\mathrm{A}$, which were included to inhibit cytochrome oxidase activity.The reaction was started with $20-50 \mu \mathrm{g}$ protein.

Latent IDPase, a commonly used marker of the Golgi body, was measured by the liberation of inorganic phosphate associated with IDP hydrolysis after incubation for $10 \mathrm{~min}$ at $30^{\circ} \mathrm{C}$ in a $0.5 \mathrm{ml}$ reaction mixture containing $5 \mathrm{~mm}$-IDP, $5 \mathrm{~mm}-\mathrm{MgCl}_{2}, 10 \mathrm{~mm}$-PIPES-Tris, pH $7.5,0.1 \mathrm{~mm}$-sodium molybdate and $40-100 \mu \mathrm{g}$ protein (Hodges \& Leonard, 1974). The reaction was stopped by addition of $0.1 \mathrm{ml} 50 \%$ (w/v) trichloroacetic acid (TCA). Latent activity was determined as shown in the enzyme latency section below.

5 -Nucleotidase is an accepted plasma membrane marker in animal cells which has also been used in fungi (Scarborough, 1975). The hydrolysis of AMP with resultant liberation of inorganic phosphate was determined in a $0.5 \mathrm{ml}$ reaction mixture containing $10 \mathrm{mM}$-AMP, 20 mM-PIPES-Tris, pH 7.5, $10 \mathrm{~mm}-\mathrm{MgSO}_{4}, 0.1 \mathrm{~mm}$-sodium molybdate and $40-100 \mu \mathrm{g}$ protein. Incubation took place for $30 \mathrm{~min}$ at $30^{\circ} \mathrm{C}$, and the reaction was stopped by the addition of TCA as above.

$1,3-\beta$-Glucan synthase is considered the most reliable enzyme marker for higher plant plasma membranes, and is also present in fungal plasma membranes. It was assayed according to the procedure described by Widell \& Larsson (1990). The assay mixture contained $50 \mathrm{~mm}$-HEPES/KOH, pH 7.25, 0.33 M-sucrose, $0.8 \mathrm{mM}$-spermine, $16 \mathrm{~mm}$-cellobiose, $4 \mathrm{~mm}$-EGTA, $4 \mathrm{mM}-\mathrm{CaCl}_{2}$ (giving $80 \mu \mathrm{M}$-free $\mathrm{Ca}^{2+}$ ), $0.01 \%$ digitonin, $1 \mathrm{~mm}-\mathrm{DTT}$ and $1-25 \mu \mathrm{g}$ protein. The reaction was started by addition of UDP- $\left[{ }^{3} \mathrm{H}\right]$ glucose $\left(30 \mathrm{GBq} \mathrm{mol}{ }^{-1}\right)$ to a final concentration of $2 \mathrm{mM}$. After $30 \mathrm{~min}$ at room temperature, the reaction was stopped by immersing the tubes in boiling water. Samples were gently filtered through filter paper (Whatman 3MM) and washed

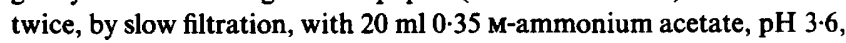
containing $30 \%(\mathrm{v} / \mathrm{v})$ ethanol. Incorporation of label in the cellobiose primer was measured by liquid scintillation.

Invertase (an extracellular enzyme which is contained in secretory vesicles) was assayed by a coupled enzyme assay involving glucose 


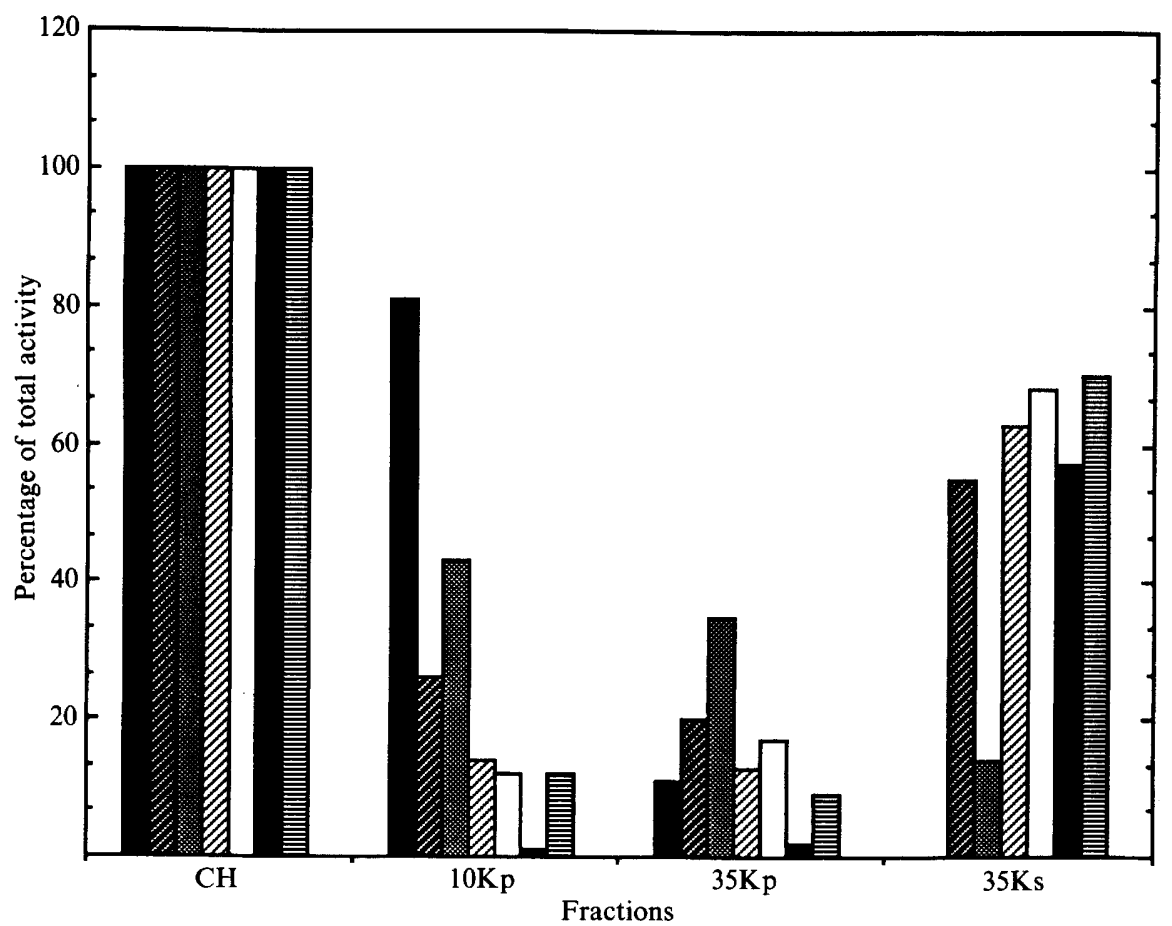

Fig. 1. Distribution of markers in fractions after differential centrifugation of the crude homogenate. Total activities (nmol min ${ }^{-1}$ ) were as follows: cytochrome oxidase ( $\square$ ), $50030 \pm 141$; NADPH-cytochrome $c$ oxido-reductase $(\square) 2097 \pm 15$; ATPase (vanadate-

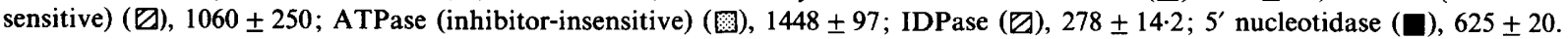
Protein (目), $185.2 \mathrm{mg}$. SEM $<14 \%$ of the mean values shown.

oxidase and peroxidase. The reaction mixture $(3 \mathrm{ml})$ contained $0.33 \mathrm{M}$ sucrose, $70 \mu \mathrm{g}$ glucose oxidase, $70 \mu \mathrm{g}$ peroxidase, $1 \mu \mathrm{M}$-dianisidine and $0.01 \%$ Triton X-100 in $50 \mathrm{~mm}$-MOPS-BTP, pH 6.0. The increase in $A_{510}$ was monitored continuously after addition of a sample containing $10-30 \mu \mathrm{g}$ of protein.

$\alpha$-Amyloglucosidase is also contained in secretory vesicles. The procedure adopted for the determination of invertase was followed, with the exception that amylose $\left(20 \mathrm{mg} \mathrm{ml}^{-1}\right)$ was used as substrate and sorbitol $(0.33 \mathrm{M})$ replaced sucrose as osmotic stabilizer. Background invertase activity resulting from the hydrolysis of residual sucrose from the membrane preparation was separately determined and deducted.

Silicotungstic acid (STA) staining. Electron microscopic observation of membrane fractions was conducted using the sample preparation methods reported previously (Ugalde \& Pitt, 1984), followed by the staining procedure described by Roland (1978). Conditions resulting in selective staining of the plasma membrane were previously defined using whole cells as controls.

Enzyme latency tests. The orientation of membrane vesicles was determined by comparison of enzyme activities in the presence and absence of detergents. Triton X-100 $(0.03 \%)$ was used in assays of vanadate-sensitive ATPase and IDPase, while $0.01 \%$ digitonin was used for $1,3-\beta$-glucan synthase. The activity in the absence of detergent was attributed to open and inside-out membrane vesicles, and that in the presence of detergent was considered as total activity. The degree of latency (which corresponds to right-side-out vesicles) was calculated as the difference between the two, and was represented as the percentage of the total activity.

Miscellaneous determinations. Inorganic phosphate was determined by the formation of a coloured phosphomolybdic complex (Kitson \& Mellon, 1944). Protein was measured according to a modified method of Lowry which incorporated the elimination of interference by nonprotein material (Bensadoun \& Weinstein, 1976).

Data are generally presented as the mean of triplicate readings per experiment, derived from at least three experiments unless stated otherwise. Standard error figures are expressed as numerical values or as a percentage fraction of the calculated mean in cases where this is required for clarity.

\section{Results}

The distribution of various organelle markers after differential centrifugation of the crude homogenate is presented (Fig. 1) in terms of percentage of the total activity. Cytochrome oxidase activity was mostly found in the $10 \mathrm{Kp}$ fraction (mitochondrial fraction), while little remained in the microsomal fraction $(35 \mathrm{Kp})$. Cytochrome $c$ oxido-reductase, 5'-nucleotidase and IDPase were found mostly in the final supernatant (35Ks), suggesting that they were not membrane-bound.

ATPase activity was partially inhibited by vanadate, and the vanadate-sensitive portion was quantified separately from the rest, which was considered as inhibitor-insensitive ATPase, given the inhibitor cocktail present in the assay medium (see Methods). Both activities display an unequal distribution pattern in Fig. 1. Inhibitor-insensitive ATPase was mostly membranebound, presenting similar distributions in the mitochon- 


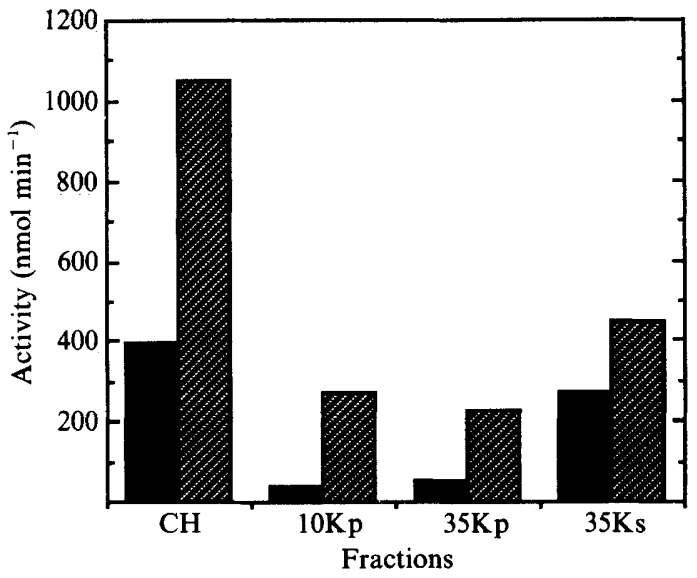

Fig. 2. Total vanadate-inhibited ATPase activities, in the absence ( $\square$ ) and presence $(\square)$ of $0.03 \%$ Triton, in fractions obtained after differential centrifugation of the crude homogenate. SEM $<12 \%$ of the mean values shown.

drial and microsomal fractions, while vanadate-sensitive ATPase activity was detected in all fractions, although the majority was in the $35 \mathrm{Ks}$ supernantant fraction. However, the activities here displayed a lower degree of latency in the presence of Triton X-100 (Fig. 2) with respect to the microsomal and mitochondrial fractions. In addition, further centrifugation of the $35 \mathrm{~K}$ supernatant at $100000 \mathrm{~g}$ for $45 \mathrm{~min}$ did not result in pelleting of this activity. It was therefore, attributed to a soluble ATPase (Gallagher \& Leonard, 1982) whilst the latent ATPase associated with the mitochondrial and microsomal fractions was taken as true plasma-membraneassociated activity. The membrane vesicles located in the microsomal fraction were comparatively more enriched in plasma membranes with respect to the mitochondrial fraction and were used in further purification steps.

The separation of the plasma membrane vesicles from the microsomal fraction in an aqueous polymer twophase system was initially calibrated by testing twophase systems of different polymer concentrations (Fig. 3 ). The results show progressive exclusion of the intracellular membrane markers cytochrome oxidase and vanadate-insensitive ATPase from the upper phase, in contrast to the plasma membrane marker (vanadatesensitive ATPase), which mostly remained in the upper phase as the polymer concentration increased. A polymer concentration of $6 \cdot 6 / 6.6 \%(\mathrm{w} / \mathrm{w})$ polyethylene glycol/dextran was chosen for further preparative work and details of the distribution of other markers under these conditions are illustrated in Table 1.

In addition to vanadate-sensitive ATPase, another recognized plasma membrane marker, 1,3- $\beta$-glucan . synthase, co-purified in the upper phase. On the other

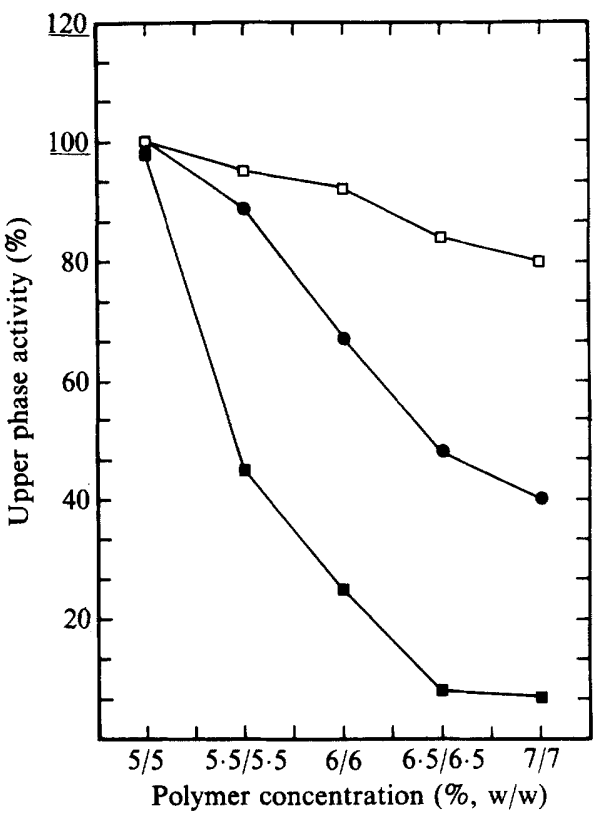

Fig. 3. Distribution of vanadate-inhibited ATPase ( $\square$ ), cytochrome $c$ oxidase ( $\square$ ) and inhibitor-insensitive ATPase $(\bullet)$ in the upper phase after a three-step batch separation using variable polyethylene glycol/dextran concentrations. Data are percentages of total activities in the two-phase system $(170 \cdot 3 \pm 4 ; 7865 \pm 165$ and $521 \pm 21 \mathrm{nmol}$ $\min ^{-1}$ respectively). SEM $<8 \%$ of the-mean values shown.

hand, Golgi body and endoplasmic reticulum marker activities collected in the lower phase, along with the mitochondrial marker. This also occurred with $5^{\prime}$ nucleotidase activity which did not follow the distribution of other commonly accepted markers of the plasma membrane. The tonoplast marker, nitrate-sensitive ATPase activity, was not detected in any of the fractions under the conditions employed.

When assays for vanadate or nitrate-inhibited ATPase were performed, a proportion of inhibitor-insensitive ATP hydrolysis was routinely detected in the upper phase fraction accompanying the plasma membrane markers, as well as in the lower phase (Fig. 3 and Table 1). In addition to being insensitive to vanadate, nitrate, molybdate, and sodium azide, which were present in the reaction mixtures, ATP hydrolysis was absolutely dependent on the presence of magnesium ions.

Latency tests carried out on the marker enzymes for different organelles indicated high levels for those corresponding to the plasma membrane, particularly in the upper phase (Table 1). This may be interpreted as the accumulation of right-side-out plasma membrane vesicles in that phase, as opposed to intracellular membranes and inside-out or open plasma membrane vesicles in the lower phase. The proportion of sealed and open plasma membrane vesicles was largely determined by the homogenization method and conditions adopted. Mild 


\section{Table 1. Distribution of marker activities}

Total activities (nmol $\mathrm{min}^{-1}$ ) for plasma membrane and other intracellular membrane markers before and after separation in an aqueous polymer two-phase system of $6.6 / 6.6 \%(\mathrm{w} / \mathrm{w})$ polyethylene glycol/dextran. Figures in brackets denote latency levels where they were observed. The $35 \mathrm{Kp}$, upper phase and lower phase fractions contained $18 \cdot 21 \pm 2,2 \cdot 82 \pm 0 \cdot 24$ and $15 \cdot 39 \pm 3 \cdot 5 \mathrm{mg}$ protein, respectively.

\begin{tabular}{|c|c|c|c|}
\hline \multirow[b]{2}{*}{ Parameter } & \multicolumn{3}{|c|}{ Activity in: } \\
\hline & $35 \mathrm{Kp}$ & Upper phase & Lower phase \\
\hline $\begin{array}{l}\text { Cytochrome } c \text { oxidase } \\
\text { NADPH-cytochrome } c\end{array}$ & $10078 \pm 50$ & $100 \pm 4$ & $8730 \pm 210$ \\
\hline oxido-reductase & $706 \pm 45$ & $134 \pm 56$ & $247 \pm 87$ \\
\hline $\begin{array}{l}\text { ATPase } \\
\text { (vanadate-sensitive) }\end{array}$ & $\begin{array}{c}220 \pm 42 \\
(58 \cdot 6 \pm 12 \%)\end{array}$ & $\begin{array}{l}157 \pm 68 \\
(93 \pm 5 \%)\end{array}$ & $\begin{array}{l}15 \cdot 51 \pm 9 \\
(25 \pm 7 \%)\end{array}$ \\
\hline $\begin{array}{l}\text { ATPase } \\
\text { (inhibitor-insensitive) }\end{array}$ & $\begin{array}{l}507 \pm 68 \\
(25 \pm 5 \%)\end{array}$ & $\begin{array}{c}158 \pm 71 \\
(36 \pm 12 \%)\end{array}$ & $\begin{array}{c}363 \pm 8 \\
(12 \pm 6 \%)\end{array}$ \\
\hline IDPase & $33 \cdot 4 \pm 1$ & $1.54 \pm 0.09$ & $\begin{array}{c}23 \cdot 4 \pm 4 \\
(35 \pm 12 \%)\end{array}$ \\
\hline $\begin{array}{l}5 \text { Nucleotidase } \\
\text { Invertase }\end{array}$ & $\begin{array}{c}12 \cdot 5 \pm 0.4 \\
19439 \pm 1500\end{array}$ & $\frac{0 \cdot 13 \pm 0}{0}$ & $\begin{array}{c}3 \cdot 5 \pm 0 \cdot 6 \\
17400\end{array}$ \\
\hline Amyloglucosidase & $9534 \pm 646$ & 0 & $6434 \pm 235$ \\
\hline $1,3-\beta$-Glucan synthase & $\begin{array}{c}53 \cdot 7 \\
(68 \%)\end{array}$ & $\begin{array}{l}24 \cdot 47 \\
(85 \%)\end{array}$ & $\begin{array}{l}16 \cdot 3 \\
(33 \%)\end{array}$ \\
\hline
\end{tabular}

Table 2. ATPase activities

Activities [nmol inorganic phosphate liberated $\min ^{-1}(\mathrm{mg} \text { protein })^{-1}$ ] and latencies recorded in the two bands collected after separation of the upper phase fraction in a Percoll density gradient.

\begin{tabular}{cccc}
\hline \hline Density $\left(\mathrm{g} \mathrm{ml}^{-1}\right)$ & Activity & + Vanadate & Latency $(\%)$ \\
\hline 1.05 & $53 \pm 4$ & $7 \pm 2$ & $93 \pm 5$ \\
$1 \cdot 10$ & $30 \pm 5$ & $24 \pm 3$ & $28 \pm 7$ \\
\hline \hline
\end{tabular}

disruption with a Potter homogenizer yielded relatively high proportions of sealed right-side-out vesicles while the use of glass beads (Ugalde \& Pitt, 1984), largely yielded open plasma membrane vesicles. These could be separated in the upper phase of a different separation system using lower polymer concentrations (results not shown).

The inhibitor-insensitive ATPase which accompanied the plasma membrane markers displayed a degree of latency which was considerably lower than the vanadatesensitive activity (Table 1) and this was considered as evidence in favour of the presence of two or more vesicle populations which could not be separated using modified two-phase systems with higher polymer concentrations (results not shown). However, Percoll density gradient centrifugation of the upper phase fraction yielded vanadate-sensitive ATPase activity, which equilibrated at a density of $1.05 \mathrm{~g} \mathrm{ml}^{-1}$ in a fraction giving a clearly visible white band, and vanadate-insensitive activity, which equilibrated at a density of $1 \cdot 1 \mathrm{~g} \mathrm{ml}^{-1}$ with a faint green band (Table 2).

Electron microscopic examination of the fractions stained with silicotungstic acid revealed specific staining of the majority of the membrane vesicles in the lower density band from the Percoll gradient as shown on Fig. 4. The membrane preparations from the microsomal fraction $(35 \mathrm{Kp})$ and the higher density band, contained a mixture of non-staining material, stained membrane vesicles (presumptive plasma membrane) and small particles in different proportions (results not shown).

The specific staining of membrane vesicles with silicotungstic acid together with the reduced levels of marker activities for intracellular membranes and the presence of vanadate-inhibited ATPase and 1,3- $\beta$-glucan synthase activities with high latencies provided strong evidence that plasma membrane vesicles of right-sideout orientation were obtained with considerable purity by the combination of separation methods used. 


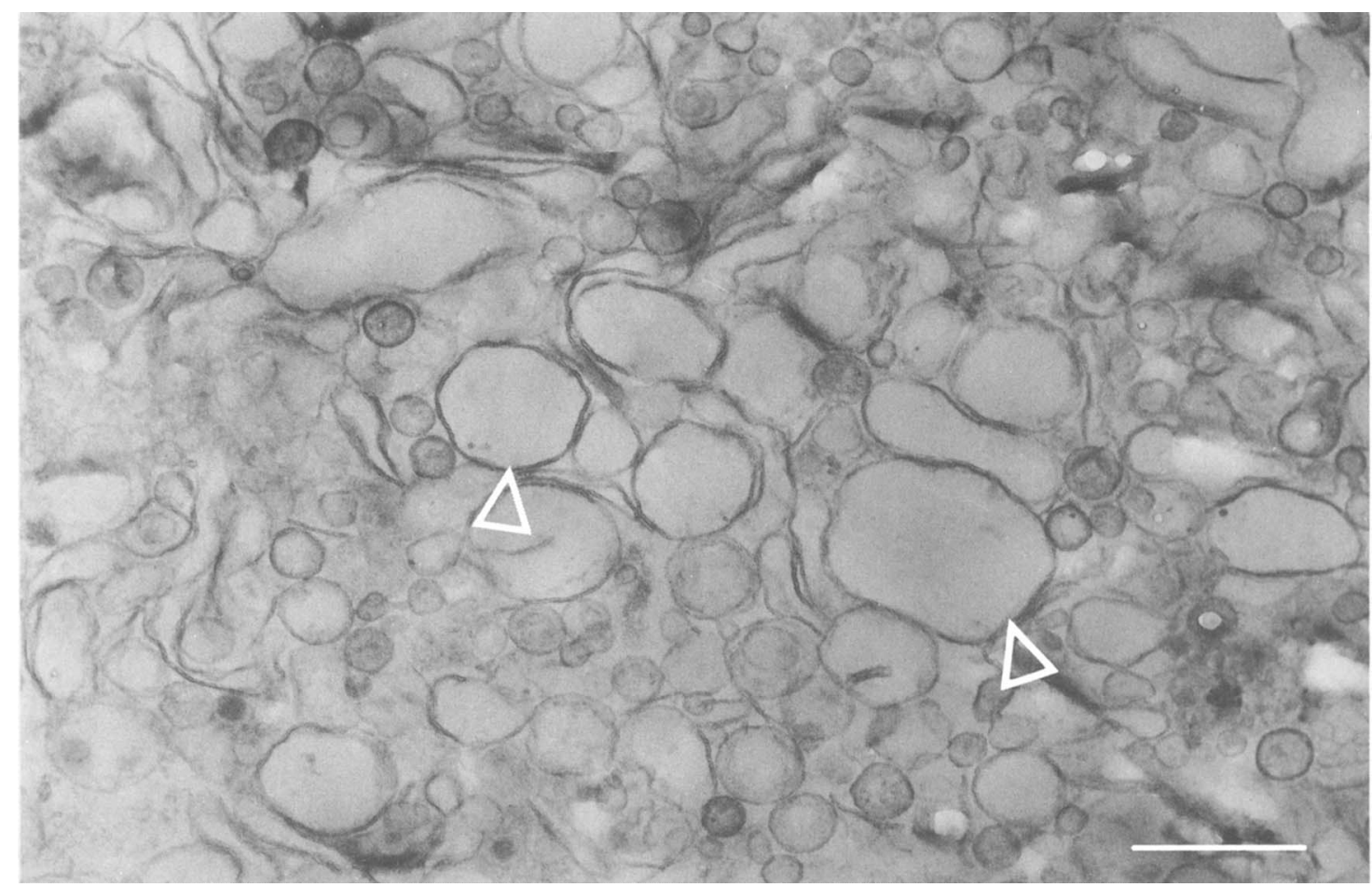

Fig. 4. Electron micrograph of the final plasma membrane preparation stained (arrows) with silicotungstic acid. Bar, $500 \mathrm{~nm}$.

\section{Discussion}

The methodology for the isolation of subcellular components is based on the assessment of yield and purity levels by means of biochemical and morphological markers (Quail, 1979). A pure subcellular fraction is that which contains its characteristic markers, but is devoid of markers from other subcellular components. Therefore, the use of a wide selection of reliable and representative markers from different parts of the cell is indispensable in a purification process.

Although the isolation of subcellular components from fungi is practised routinely, information regarding the assignment of marker activities is sparse and largely based on knowledge from plant and animal systems, which may not be extrapolated in all cases, as has been shown even between different tissues (reviews, Quail, 1979; Widell \& Larsson, 1990).

In this study, the distribution of some of the most commonly used markers in the isolation of fungal plasma membrane vesicles has been assessed, and in a number of cases activities were distributed in more than one location. This common feature termed overrepresentation (Quail, 1979) was observed with vanadate-sensitive ATPase, IDPase, 5'-nucleotidase and NADPH-cytochrome $c$ oxido-reductase, as they could be found in membrane-bound and solubilized form. Glucan synthase was determined in membrane fractions only and the distribution in the two-phase system could be due to the partition pattern of plasma membrane fragments or vesicles of various orientations, as well as the presence of this marker in secretion vesicles

A soluble form of vanadate-sensitive ATPase similar to that described in corn roots (Gallagher \& Leonard, 1982) has been found, and the evidence obtained in this study suggests that the only vanadate-sensitive ATPase in the particulate fractions corresponds to the plasma membrane enzyme. However, this activity may easily be masked in fractions where comparatively large proportions of inhibitor-insensitive ATPase are present, and it is therefore reliably measured only after partial purification. The inhibitor-insensitive ATPase is abundant in the microsomal fraction, which suggests that it may be associated with membranes in the secretion pathway, which would be expected in large quantities in young and rapidly growing cultures such as those used. A vanadateinsensitive Golgi-associated ATPase has been reported in plants (Ali \& Akazawa, 1986; Hager \& Biber, 1984).

IDPase activity appears to be found mostly in soluble form, which may also be due to interference by molybdate-resistant phosphatases (Bowman \& Bowman, 1982), or non-specific nucleotide diphosphatases (Vara \& Serrano, 1981; Morré, 1990). The form found in particulate fractions demonstrates some latency, and 
could correspond to the membrane-bound activity described in Golgi and secretory vesicles (Chanson et al., 1984; Camirand et al., 1987; Morré et al., 1977). However, the levels of IDPase activity detected in this system, in clear contrast with the vanadate-insensitive ATPase, are very low and are problably not representative of the distribution of Golgi bodies within the intact cell.

$5^{\prime}$-Nucleotidase (EC 3.1.3.5) has been widely used as a convenient and reliable marker for animal plasma membranes. However, reports suggest that it is not a suitable plasma membrane marker in fungal systems (Scarborough, 1975; Marriott, 1975). The results obtained in this study show that its activity is mostly in soluble form and that the low levels associated with particulate fractions are not associated with the plasma membrane.

The most commonly used marker for the endoplasmic reticulum, NADPH-cytochrome $c$ oxido-reductase, was found in soluble and membrane fractions. Some activity remained in the plasma membrane fraction of Penicillium cyclopium. Although it has been reported to be mostly associated with the endoplasmic reticulum, other locations including the plasma membrane have been reported (Widell \& Larsson, 1990). Redox processes occurring at the level of the plasma membrane in plants have been described (Møller \& Crane, 1990) which have also been observed in $P$. cyclopium (W. Roos, personal communication) and could involve this enzyme. Thus, the presence of this activity in plasma membrane fractions does not necessarily indicate contamination by the ER.

Tonoplast membrane has been reported to contain nitrate-inhibited ATPase in plant systems (Sze, 1985), and tonoplast vesicles of Penicillium cyctopium have been isolated which contain this activity (W. Roos, personal communication). However, it was undetectable in this study, possibly due to the short incubation period ( $24 \mathrm{~h})$ chosen for the production of biomass, in which relatively few vacuoles could be seen in hyphae in comparison with older cultures. The use of alternative markers, such as $\alpha$ mannosidase had previously been dismissed on the basis of reported low activities in other fungi (Bowman $e t$ al., 1981).

One of the most reliable markers for the plasma membrane in plant systems is $1,3-\beta$-glucan synthase (Widell \& Larsson, 1990), and in yeast it is mostly associated with the plasma membrane, in contrast with chitin synthase, which is also found in chitosomes (LealMorales et al., 1988). In the present study the marker accompanied the activity of vanadate-sensitive ATPase and showed comparable levels of latency. The activity remaining in the lower phase showed low latency levels, and could be due to activity in inside-out vesicles and/or secretion vesicles whose zymogenic form may have been activated by the action of proteases during sample manipulation.

The specific staining of plant plasma membranes in situ using phosphotungstic and silicotungstic acid (Roland et al., 1972) has been widely used as a morphological marker to determine purity in plasma membrane fractions, with some criticism regarding specificity (Boss \& Ruesink, 1979; Nagahashi et al., 1978; Quail, 1979). However, strict control of staining conditions using whole cells results in a high degree of specificity with subcellular fractions (Sandelius et al., 1986; Kjellbom \& Larsson, 1984; Morré, 1990) and this has been shown also to be true for fungal material in this study. Moreover, electron micrographs of the final preparation show little contamination by non-plasma-membrane material, which suggests that the plasma membrane preparation is of very high purity.

The coincidence of all three markers (vanadatesensitive ATPase, 1,3- $\beta$-glucan synthase and silicotungstic acid staining) chosen for the determination of the plasma membrane, and the near absence of activities corresponding to other subcellular components, confirms that the plasma membrane vesicles obtained by a combination of aqueous polymer two-phase partitioning and density gradient centrifugation yields a preparation of exceptionally pure plasma membrane vesicles.

Latency tests with vanadate-sensitive ATPase and 1,3$\beta$-glucan synthase reveal that these enzyme activities may be increased several-fold in the presence of detergents and this leads to the conclusion that the majority of the vesicles are in the right-side-out configuration (i.e., the plasma membrane has the same orientation as in the living organism). However, detergents are also known to influence the kinetic properties of enzymes such as the plasma membrane ATPase of yeasts and plants (Monk et al., 1989; Palmgren et al., 1990). Such kinetic effects have not been examined in this study, but the detergent concentrations used are below those reported to alter the kinetic properties of these enzymes, so the latency values reported are probably not influenced by this artefact.

We thank the University of the Basque Country and Diputacion Foral de Guipuzcoa for financial support to the project. We are also grateful to Prof. C. Larsson for helpful discussions regarding experimental design and elaboration of the manuscript. U.O.U. was the recipient of a Basque Govt. research exchange grant with the University of Lund during the course of the project.

\section{References}

Ali, M. D. \& Akazawa, T. (1986). Association of $\mathrm{H}^{+}$-translocating ATPase in the Golgi membrane system from suspension-cultured cells of sycamore (Acer pseudoplanatus L). Plant Physiology 81, 222227 . 
Bensadoun, A. \& Weinstein, D. (1976). Assay of proteins in the presence of interfering materials. Analytical Biochemistry 7, 241-250.

Boss, W. F. \& RUESINK, A. W. (1979). Isolation and characterization of concanavalin A-labelled plasma membranes of carrot protoplasts. Plant Physiology 64, 1005-1011.

Bowman, E. J. \& BowmaN, B. J. (1982). Identification and properties of an ATPase in vacuolar membranes of Neurospora crassa. Journal of Bacteriology 151, 1326-1337.

Bowman, B. J. \& Slayman, C. W. (1979). The effects of vanadate on the plasma membrane ATPase of Neurospora crassa. Journal of Biological Chemistry 254, 2928-2934.

Bowman, E. J., Bowman, B. J. \& Slayman, C. W. (1981). Isolation and characterization of plasma membranes from wild-type Neurospora crassa. Journal of Biological Chemistry 256, 12336-12342.

Camirand, A., Brummell, D. \& Maclachlan, G. (1987). Fucosilation of xyloglucan: localization of the transferase in dyctiosomes of pea stem cells. Plant Physiology 84, 753-756.

Canut, H., Brightman, A. O., Boudet, A. M. \& MorRé, J. D. (1987) Determination of sidedness of plasma membranes and tonoplast vesicles isolated from plant stems. In: Plant Membranes: Structure, Function, Biogenesis, pp. 141-159. New York: Alan R. Liss.

Chanson, A., McNaughton, E. \& Taiz, L. (1984). Evidence for a $\mathrm{KCl}$-stimulated, $\mathrm{Mg}^{2+}$-ATPase on the Golgi of corn coleoptiles. Plant Physiology 76, 498-507.

CoOperstein, S. J. \& Lazarow, A. (1951). A microspectrophotometric method for the determination of cytochrome oxidase. Journal of Biological Chemistry 189, 665-670.

Franzusoff, A. J. \& Cirillo, V. P. (1983). Glucose transport activity in isolated plasma membrane vesicles from Saccharomyces cerevisiae. Journal of Biological Chemistry 258, 3608-3614.

Fuhrmann, G. F., Boehm, C. \& Theuvenet, A. P. R. (1976). Sugar transport and potassium permeability in yeast plasma membrane vesicles. Biochimica et Biophysica Acta 433, 583-596.

GallagheR, S. R. \& LeONARD, R. T. (1982). Effect of vanadate, molybdate and azide on membrane-associated ATPase and soluble phosphatase activities of corn roots. Plant Physiology 70, 1335-1340.

HAGER, A. \& BIBER, W. (1984). Functional and regulatory properties of $\mathrm{H}^{+}$pumps at the tonoplast and plasma membranes of Zea mays coleoptiles. Zeitschrift fur Naturforschung 39c, 927-937.

Hodges, T. K. \& Leonard, R. T. (1974). Purification of a plasma membrane-bound adenosine triphosphatase from plant roots. Methods in Enzymology 32, 392-407.

Kitson, R. E. \& MELlon, M. (1944). Further studies of the molybdenum blue reaction. Industrial and Engineering Chemistry 16, $466-469$.

KJellbom, P. \& Larsson, C. (1984). Preparation and polypeptide composition of chlorophyll-free plasma membranes from leaves of light-grown spinach and barley. Physiologia Plantarum 62, 501-509.

Larsson, C., KJellbom, P., Widell, S. \& LundborG, T. (1984). Sidedness of plant plasma membrane vesicles purified by partitioning in aqueous two-phase systems. FEBS Letters 171, 271-276.

LaRsson, C., Widell, S. \& KJELlbom, P. (1987). Preparation of highpurity plasma membranes. Methods in Enzymology 148, 558-568.

Leal-Morales, C. A., Bracker, C. E. \& Bartnicki-Garcia, S. (1988). Localization of chitin synthase in cell-free homogenates of Saccharomyces cerevisiae: chitosomes and plasma membrane. Proceedings of the National Academy of Sciences of the United States of America 85, 8516-8520.

MARRIOTT, M. S. (1975). Enzymatic activity of purified plasma membranes from yeast and mycelial forms of Candida albicans. Journal of General Microbiology 89, 345-352.

Møller, I. M. \& CRANE, F. L. (1990). Redox processes in the plasma membrane. In The Plant Plasma Membrane, pp. 93-126. Berlin: Springer.
Monk, B. C., Montesinos, C., Leonard, K. \& Serrano, R. (1989). Sidedness of yeast plasma membrane vesicles and mechanisms of activation of the ATPase by detergents. Biochimica et Biophysica Acta 981, 226-234.

MORRÉ, D. I. (1990). Plasma membrane cytochemistry. In The Plant Plasma Membrane, pp. 76-92. Berlin: Springer.

Morré, D. I., Lembi, C. A. \& VAN DeR WOUde, W. J. (1977). A latent inosine-5'-diphosphatase associated with Golgi-apparatus-rich fractions from onion stem. European Journal of Cell Biology 16, 7281 .

Nagahashi, G., Leonard, R. T. \& Thomson, W. H. (1978). Purification of plasma membranes from roots of barley. Plant Physiology. 61, 993-999.

NørвY, J. G. (1988) Coupled assay of $\mathrm{Na}^{+}, \mathrm{K}^{+}$-ATPase activity. Methods in Enzymology 156, 116-119.

Palmgren, M. G. \& Sommarin, M. (1989). Lysophosphatidylcholine stimulates ATP-dependent proton accumulation in isolated oat root plasma membrane vesicles. Plant Physiology 90, 1009-1014.

Palmgren, M. G., Sommarin, M., Ulvkov, P. \& Larsson, C. (1990). Effect of detergents on the $\mathrm{H}^{+}$-ATPase activity of inside-out and right-side-out plant plasma membrane vesicles. Biochimica et Biophysica Acta 1021, 133-140.

QuaIL, P. H. (1979). Plant cell fractionation. Annual Review of Plant Physiology 30, 425-484.

RANDALL, S. K. \& RUESINK, A. W. (1983). Orientation and integrity of plasma membrane vesicles obtained from carrot protoplasts. Plant Physiology 73, 385-391.

RolaND, J. C. (1978). General preparation and staining of thin sections. In Electron Microscopy and Cytochemistry of Plant Cells, pp. 1-62. Edited by J. L. Hall. Amsterdam: Elsevier.

Roland, J. C. Lembi, C. A. \& MorRé, D. J. (1972). Phosphotungstic acid-chromic acid as a selective electron-dense stain. Stain Techno$\log y$ 47, 195-200.

Sandelius, A. S., Penel, C., Auderset, G., Brightman, A., Millard, M. \& MoRRÉ, D. J. (1986). Isolation of highly purified fractions of plasma membrane and tonoplast from the same homogenate of soybean hypocotyls by free-flow electrophoresis. Plant Physiology 81, 177-185.

SCARBOROUGH, A. (1975). Isolation and characterization of Neurospora crassa plasma membranes. Journal of Biological Chemistry 10, 11061111.

SCHEKMAN, R. (1982). Biochemical markers for yeast organelles. In The Molecular Biology of the Yeast Saccharomyces, pp. 651-652. Cold Spring Harbor, NY: Cold Spring Harbor Laboratory.

Stroobant, P. \& SCARBorovgh, G. A. (1979). Large scale isolation and storage of Neurospora plasma membranes. Analytical Biochemistry $95,554-558$.

SzE, H. (1985). $\mathrm{H}^{+}$-Translocating ATPases: advances using membrane vesicles. Annual Review of Plant Physiology 67, 175-208.

Ugalde, U. O. \& PITT, D. (1983). Morphology and calcium-induced conidiation of Penicillium cyclopium in submerged culture. Transactions of the British Mycological Society 80, 319-325.

Ugalde, U. O. \& PITT, D. (1984). Subcellular sites of calcium accumulation and relationships with conidiation in Penicillium cyclopium. Transactions of the British Mycological Society 83, 547-555.

UgaldE, U. O., VIRTO, M. D. \& PITT, D. (1990). Calcium binding and induction of conidiation in protoplasts of Penicillium cyclopium. Antonie Van Leeuwenhoek 57, 43-49.

Vara, F. \& Serrano, R. (1981). Purification and characterisation of a membrane-bound ATP diphosphorylase from Cicer arietinum (chickpea) roots. Biochemical Journal 197, 637-643.

WIDELL, S. \& LARSSON, C. (1990). A critical evaluation of markers used in plasma membrane purification. In The Plant Plasma Membrane, pp. 16-43. Berlin: Springer. 